Katarzyna Szopa

Uniwersytet Śląski w Katowicach

\title{
Fitting bodies: Kulturowa polityka rozmiaru ciała
}

Każdy z nas może jednego dnia pasować tu i teraz, a jutro nie pasować już nigdzie ${ }^{1}$.

Cusie Orbach spostrzegła, że stopniowo „tracimy ciała” i żyjemy w świecie, Ww którym wytwarzane są „ciała na miarę” - dopasowane do standardów kultury zachodniej. Swoista „produkcja” ciał przykrajanych na miarę spowodowana jest, wedle Orbach, napierającą zewsząd hegemonią kultury wizualnej i medialnej, która, w zamian za pozbycie się tożsamości obfitujących w różnorodność, oferuje „tosamość”. Co więcej, ciała dopasowane, idealne i nieskazitelne, wykreowane przez koncerny kosmetyczne i spożywczo-dietetyczne, a także przez przemysł chirurgii plastycznej, wytwarzają szczelne granice pomiędzy centrum a wykluczonym marginesem ${ }^{2}$. Globalizacja jako nowoczesna forma imperializmu anektuje każdą przestrzeń, nie tylko rozumianą w kategoriach geograficznych czy architektonicznych, ale przede wszystkim przestrzeń cielesną. Ten cielesny kolonializm, jak nazywa to zjawisko Orbach, wykorzenia nas nie tylko z własnych ciał, ale też z macierzystych języków ${ }^{3}$.

Kategorie „dopasowania” i „niedopasowania” stały się odpowiedzią na dominujący paradygmat jednego, uniwersalnego rozmiaru ciała (one-size -fits-all) w kulturze zachodniej. Rosemarie Garland-Thomson w koncepcji określanej przez siebie jako misfitting tropi właśnie ciała niedopasowane,

${ }^{1}$ Rosemarie Garland-Thomson, Misfits: A Feminist Materialist Disability Concept, „Hypatia” 2011, vol. 26, issue 3, s. 597. Tam, gdzie nie zaznaczono inaczej, cytaty ze źródeł obcojęzycznych podaję w tłumaczeniu własnym.

${ }^{2}$ Susie Orbach pisze: „W Szanghaju najmodniejsza operacja to łamanie uda i wydłużanie nogi o dziesięć centymetrów. W Singapurze ostatnim krzykiem mody jest zachodni nos. W Europie Wschodniej szczupłość stała się wymogiem wśród młodzieży chcącej wkroczyć w kulturę globalną. W Korei Południowej 50 proc. nastolatek poddaje się operacji podnoszenia powieki na wzór zachodniego wyglądu powieki oka”. Susie Orbach, Losing Bodies, „Social Research” 2011, vol. 78, no. 2, s. 389.

3 Ibidem, s. 394. 
nie mieszczące się w ramach zachodnich standardów. Zdaniem badaczki, dopasowanie i niedopasowanie zależą od kontekstu, czyli od miejsca, rasy, klasy czy płci, dlatego też figura odmienności (misfit) staje się przeciwwagą wobec tradycyjnie pojmowanego pojęcia nieodpowiedniości.

Fitting i misfitting - pisze Garland-Thomson - oznacza spotkanie, w którym dwie rzeczy łączą się albo w harmonii, albo w dysjunkcji. Kiedy kształt i substancja tych dwóch rzeczy korespondują w momencie ich zjednoczenia, wtedy pasują. Niedopasowanie, odwrotnie, oznacza nieharmonijną relację pomiędzy dwiema rzeczami: kwadratowy kołek w okrągłej dziurze. Problem z niedopasowaniem tkwi zatem nie w którejkolwiek z tych rzeczy, ale raczej w ich zestawieniu, w niezgrabnym usiłowaniu dopasowania ich do siebie ${ }^{4}$.

Garland-Thomson dowodzi, że problem tkwi właśnie w próbie zestawiania i porównywania, co automatycznie prowadzi do sytuacji akceptowania lub wykluczania. Badaczka, podobnie jak Susie Orbach, dostrzega, że dominującym założeniem kultury zachodniej jest dopasowanie siebie do świata tak, by nasze kształty i nasze ciała były „stabilne”, „zorganizowane” i „przewidywalne”, a tym samym, mówiąc po Foucaultowsku, uległe i poddane kontroli. Jednocześnie potrzebujemy figur granicznych i potwornych do utrzymania porządku - do tego, by uzmysłowić sobie, czym nie jesteśmy i czym nie powinniśmy się staćs.

Przyglądając się lansowanym przez popkulturę wizerunkom ciał, obserwujemy ekspansję „odcieleśnionych obrazów”, pomiędzy którymi zniwelowane zostały wszelkie różnice płciowe, klasowe, etniczne i rasowe. To ciała bez historii, bez korzeni i bez własnego języka, ciała, które, zdaniem Elspeth Probyn, doświadczyły wykluczenia z przestrzeni (out-of-place) ${ }^{6}$. Zintensyfikowanie wizerunków ciał, spełniających obowiązujące kulturowe kryteria wymiarów, doprowadza do paradoksalnej sytuacji, w której ciała dopasowuje się do kształtu świata, a nie odwrotnie. To właśnie rozbieżność między ciałem i światem, między tym, czego się oczekuje a tym, co po prostu jest, wytwarza zjawiska dopasowania i wykluczenia7. Tym samym, tworząca się przestrzeń, w obrębie której nie mieści się margines odmienności (w tym przypadku otyłości), sprowadza się do takich fenomenów, jak kult anoreksji i bulimii, traktowanych jako nowe filozofie życia (tzw. thinspiration), a także do powszechnej histerii związanej z otyłością (tzw. fatphobia). W związku z przesunięciem paradygmatu z chorób jakimi są zaburzenia odżywiania w stronę nowej estetyki, stajemy wobec nowego zjawiska, jakim jest „zabu-

4 Rosemarie Garland-Thomson, op. cit., s. 592-593.

5 Por.: Kim Toffoletti, Cyborgs and Barbie Dolls. Feminism, Popular Culture and the Posthuman Body, I.B. Tauris, London, New York 2007, s. 84.

${ }^{6}$ Por.: Elspeth Probyn, Everyday Shame, „Cultural Studies” 2004, vol. 18, no. 2-3, s. 329.

7 Por.: Rosemarie Garland-Thomson, op. cit., s. 593. 
rzenie rozmiaru" (sizing disorder). Podmioty/ciała niepasujące będą zatem, wedle słownika, albo „za małe”, albo „za duże” w zestawieniu z idealnym rozmiarem, ukształtowanym wedle miary kultury zachodniej.

\section{Cielesne topografie}

Zarówno ciało anorektyczki, bulimiczki, jak i kobiety otyłej nie mieści się w ściśle wytyczonych granicach i wymiarach. To ciało, w zestawieniu z wymaganym standardem, nie pasuje: zaburza porządek, wzbudza obrzydzenie, zmusza do odwrócenia wzroku, ale też, jak pisze Elspeth Probyn, zawstydza ${ }^{8}$. Anorektyczne praktyki samogłodzenia stały się nowym sposobem dyscyplinowania ciała - kobiety, jak powiadają badaczki zaburzeń odżywiania, poszcząc, głodząc się i stosując diety, renegocjują granice siebie poprzez manipulowanie rozmiarem własnego ciała ${ }^{9}$. Etiologii choroby należy poszukiwać w religii, w praktykowaniu ascezy, której przykładem jest żywot św. Katarzyny ze Sieny (tzw. anorexia mirabilis) ${ }^{10}$.

Praktyki głodzenia się są różnie interpretowane przez badaczy - albo jako pragnienie zniknięcia i osiągnięcia stanu niewidzialności, albo też jako ślepe podążanie za modą; mówi się też o pragnieniu osiągnięcia samokontroli, która w efekcie przybiera formy patologicznej rebelii „ja” wobec własnej cielesności. Krytyczki feministyczne wielokrotnie podkreślały, że anoreksja, podobnie jak niegdyś histeria, postrzegana jest przez społeczeństwo jako kolejny kobiecy wybryk, a nawet kaprys, co obniża rangę choroby i sprowadza ją do problemu magazynów mody i programów telewizyjnych, czyniąc tym samym problem zaburzeń odżywiania kolejną maladie imaginaire ${ }^{11}$. Ciało anorektyczki jawi się jednakże jako groteskowa parodia kulturowego ideału kobiecości. Badaczki feministyczne dostrzegają również jego subwersywny potencjał: głodzenie się, „gaśnięcie, umieranie, osiągnięcie stanu ulotności może oznaczać nie tylko destrukcję siebie, ale też subwersywne i oporne uchylanie się przed dyscyplinującym, indywidualizującym i nadającym płeć [gender-ing] spojrzeniem" ${ }^{12}$.

8 Por.: Elspeth Probyn, Eating disgust, feeding shame, [w:] eadem, Carnal Appetites. Food, Sex, Identities, Routledge, London, New York 2005, s. 128.

${ }^{9}$ Por.: Helen Gremillion, The Cultural Politics of Body Size, „Annual Review of Anthropology" 2005, vol. 34, s. 20.

10 Zob.: Caroline Giles Banks, „There is No Fat in Heaven”: Religious Asceticism and the Meaning of Anorexia Nervosa, „Ethos” 1996, vol. 24, no. 1, s. 107-135.

${ }^{11}$ Por.: Helen Malson, The Thin Woman. Feminism, Post-structuralism and the Social Psychology of Anorexia Nervosa, Taylor \& Francis, London 1998, s. 73.

${ }_{12}$ Helen Malson, Jane Ussher, Beyond This Mortal Coil: Femininity, Death and Discursive Constructions of the Anorexic Body, „Mortality” 1997, vol. 2, issue 1, s. 56. 
„Brzydką siostrą” anoreksji jest bulimia, której praktyki kompulsywnego jedzenia i przymusowego wydalania świadczą o braku kontroli ${ }^{13}$. Wśród społeczności Pro-Any ${ }^{14}$ praktyki bulimiczek są stygmatyzowane i postrzegane jako zagrożenie. Podczas gdy anoreksja jest świadomym wyborem i filozofią życia, bulimia postrzegana jest jako „mniej ambitny wybór”. Co więcej, w badaniach nad zaburzeniami odżywiania bulimia jest chorobą marginalizowaną - badacze, a nawet krytyczki feministyczne, do tej pory poświęcali więcej uwagi problemowi anoreksji ${ }^{15}$. Ciała bulimiczek bowiem pozornie, na co zwraca uwagę Sarah Squire, są ciałami dopasowanymi, spełniającymi wymagane kryteria rozmiarów. Jednakże ich praktyki odbywają się w ukryciu, co dodatkowo potęguje narastające poczucie winy. „W momencie objadania się i wydalania - jak pisze Squire - integralność ciała ulega pęknięciu, a iluzja samopowstrzymywania się zostaje rozwiana"16. Ciało bulimiczki, nieustannie zestawiane z wychudzonym obrazem anorektyczki, sytuuje się, mówiąc językiem Julii Kristevej, jako społeczny abiekt ze względu na odrażające praktyki wydalania. To absolutny nadmiar, bowiem ciało abiektalne, którym staje się ciało bulimiczki, nie mieści się w społecznym porządku, a posługując się metaforyką cieczy (jak łzy, ślina czy wymioty) Kristeva pokazuje, że abiekt symbolizuje niekontrolowaną i niebezpieczną anarchię w obrębie społecznego organizmu ${ }^{17}$.

Zarówno ciało anorektyczki, jak i bulimiczki, wykracza poza schematyczne ramy ciał dopasowanych. Jednakże w obrębie tego marginesu

${ }_{13}$ Por.: Sarah Squire, Anorexia and Bulimia: Purity and Danger, „Australian Feminist Studies" 2003, vol. 18, issue 40, s. 19.

${ }_{14}$ Pro-Ana jest zamkniętą społecznością internetową (pro-eating disorder's website), w obrębie której nawołuje się do praktykowania i kultywowania anoreksji, a jej użytkowniczki i użytkownicy przeciwni są wyzdrowieniu. Anoreksja staje się więc nowym rodzajem filozofii życia. Odpowiednikiem Pro-Any jest Pro-Mia, czyli społeczność kultywująca i praktykująca bulimię. Por.: Katy Day, Tammy Keys, Anorexia/Bulimia as Resistance and Conformity in Pro-Ana and Pro-Mia Virtual Conversations, [w:] eds. Maree Burns, Helen Malson, Critical Feminist Approaches to Eating Dis/Orders, Routledge, New York 2009, s. 87-96; Sarah R. Brotsky, David Giles, Inside the „Pro-Ana” Community: a Covert Online Participant Observation, „Eating Disorders: The Journal of Treatment and Prevention” 2007, vol. 15, no 2, s. 93-109.

15 Por.: Maree Burns, Eating Like an Ox: Femininity and Dualistic Constructions of Bulimia and Anorexia, „Feminism \& Psychology” 2004, vol. 14, no. 2, s. 271.

${ }^{16}$ Sarah Squire, op. cit., s. 23.

17 „Abiekt” (fr. l'ab-ject), dosłownie oznaczający 'wymiot', Kristeva przeciwstawia „obiektowi”, czyli podmiotowi. Abiekt, określany w języku polskim jako 'pomiot', stanowi byt marginalizowany, któremu odmawia się prawa do podmiotowości, a co za tym idzie, do pełnoprawnego funkcjonowania w obrębie porządku społecznego. Pojęcie to w psychoanalizie symbolizuje zarówno wstręt do siebie, jak i rozpad podmiotu, który istnieje poza porządkiem symbolicznym. Por.: Julia Kristeva, Potęga obrzydzenia. Esej o wstręcie, przeł. Maciej Falski, Wydawnictwo Uniwersytetu Jagiellońskiego, Kraków 2007, s. 7-14. 
nieporządku kryje się również ciało charakteryzujące się swoistym nadmiarem w sensie wizualnym i estetycznym. Poszukując ciał niedopasowanych, Susie Orbach ponad 30 lat temu dowiodła w, wydanej pod znamiennym tytułem, książce Fat Is a Feminist Issue, że otyłość powinna stać się kwestią kluczową dla badań feministycznych. Wtórujące jej krytyczki, jak Susan Bordo w Unbearable Weight, Naomi Wolf w Micie piękności i Elaine Showalter w swoich „histerycznych narracjach”, badały zjawiska zaburzeń odżywiania wśród kobiet ${ }^{18}$. Badaczki przede wszystkim poruszały kwestie wpływu kultury medialnej oraz terroru piękności na postrzeganie przez kobiety własnego ciała. Przy czym punkt ciężkości ich rozważań skupiał się na anoreksji. Ciało otyłe doświadczało podwójnego wykluczenia, również $\mathrm{w}$ dyskursie feministycznym ${ }^{19}$; zostało wyparte i skazane na bytowanie na pograniczach. I, co paradoksalne, stało się niewidzialne.

Jak zauważa Rosi Braidotti, kategoria naddatku czy nadmiaru (too much) wzbudza strach wynikający z transgresji poza wyznaczony porządek ${ }^{20}$. To, co wykracza i przełamuje normatywne schematy, w efekcie postrzegane jest jako patologiczne. Otyłość jest patologiczna również w dyskursie medycznym i wpisuje się w paradygmat kobiecej inności i kobiecego nadmiaru ${ }^{21}$. W kulturze zachodniej tłuszcz ( fat) utożsamiany jest ze złem²2. Jak zauważa Richard Klein:

jest czymś, co mamy na sobie, i co znajduje się na zewnątrz naszych wnętrz. Właściwie nie należy do nas i nie należy do miejsca, w którym go znajdujemy. Marzymy o usunięciu go, o pozostawieniu naszych ciał nie tylko nietkniętymi i niezmienionymi, ale też bardziej czystymi, bo bardziej chudymi ${ }^{23}$.

${ }^{18}$ Por.: Susie Orbach, Fat is a Feminist Issue, Arrow Books, London 1998; Susan Bordo, Unbearable Weight: Feminism, Western Culture, and the Body, University of California Press, Berkeley, Los Angeles 2003; Naomi Wolf, The Beauty Myth: How Images of Beauty are Used Against Women, Morrow, New York 1991; Elaine Showalter, Hystories. Hysterical Epidemics and Modern Culture, Columbia University Press, New York 1997.

19 Por.: Petra Jonvallen, Sex Differentiation and Body Fat: Local Biologies and Gender Transgressions, „European Journal of Women's Studies” 2010, vol. 17, no. 4, s. 386; Kathleen LeBesco, Jana Evans Braziel, Editors' Introduction, [w:] eds. Jana Evans Braziel, Kathleen LeBesco, Bodies Out of Bounds. Fatness and Transgression, University California Press, Berkeley-Los Angeles-London 2001, s. 6.

${ }^{20}$ Por.: Rosi Braidotti, Metamorphoses: Towards a Materialist Theory of Becoming, Wiley, Cambridge 2002, s. 141.

${ }^{21}$ Por.: Georges Vigarello, Historia otyłości od średniowiecza do XX wieku, przeł. Anna Leyk, Wydawnictwo Aletheia, Warszawa 2012.

${ }^{22}$ Por.: Richard Klein, Fat Beauty, [w:] eds. Jana Evans Braziel, Kathleen LeBesco, Bodies Out of Bounds. Fatness and Transgression, University California Press, Berkeley, Los Angeles, London 2001, s. 37.

${ }^{23}$ Ibidem, s. 27. 
Usunięcie tłuszczu, obsesyjne próby pozbycia się go, popierane są licznymi badaniami medycznymi, mówiącymi o ryzyku zdrowotnym, a także moralnymi i estetycznymi twierdzeniami, jakoby ciało otyłe reprezentowało lenistwo, brak kontroli, brzydotę i aseksualnośćc ${ }^{24}$. Co więcej, „tłuszcz - jak pisze Rachel Colls - znajduje się na ciele pod skórą i dlatego nie «wycieka na zewnątrz» w ten sam sposób, co łzy, ślina i wymiociny. Jest niejednoznaczny: jednocześnie umiejscowiony pod skórą, a już zmaterializowany jako substancja odrębna, występująca sama w sobie"25. Otyłość, jak i sam tłuszcz, jest zatem stanem wykraczającym poza właściwe granice ciała i miejsca stąd też „lęki przestrzenne” wśród osób otyłych, które odczuwają obawę przed zajmowaniem zbyt wiele miejsca. Natomiast „figura «kobiety jako nadmiaru» jest ostentacyjna”. Jak dalej pisze Helen Malson, „we współczesnych dyskursywnych konstrukcjach kobieta mówi za dużo, wykazuje się nadmierną emocjonalnością, ma zbyt wiele potrzeb, zajmuje zbyt wiele miejsca i jest jej «wszędzie pełno»" ${ }^{26}$. By zyskać akceptację, kobiece ciało musi być mniejsze od męskiego, dlatego też wychudzone i dopasowane ciało jest hiperseksualne, w przeciwieństwie do aseksualnej tuszy.

\section{Dermografie - perspektywa feministyczna}

Analizując zależność między jedzeniem, wstrętem i wstydem, Elspeth Probyn opisuje cielesne reakcje na widok anorektycznego i otyłego ciała. Zdaniem badaczki, wstręt wzbudza w nas to, co niewygodne, co nie mieści się w ramach określonego porządku i co znajduje się zbyt blisko nas ${ }^{27}$. Z kolei wstyd to osobliwy moment, w którym ciało chwilowo nie pasuje do otoczenia, kiedy dosłownie znajduje się „poza miejscem” ${ }^{28}$. Doświadczając zarówno wstrętu, jak i wstydu ciało uruchamia najwięcej zmysłów i reaguje w sposób specyficzny, wręcz paradoksalny - podczas gdy wstręt nas odpycha, to wstyd przyciąga. Kombinacja wstydu i wstrętu jako dwóch najistotniejszych, według Probyn, afektów produkuje nową, cielesną wiedzę - wstręt reguluje różnicę między cielesnym wnętrzem a zewnętrzem i tym, co powinno a co nie powinno zostać wpuszczone do środka; natomiast wstyd, jako hiperre-

${ }^{24}$ Por.: Rachel Colls, Materialising Bodily Matter: Intra-Action and the Embodiment of „Fat”, „Geoforum” 2007, vol. 38, issue 2, s. 354.

${ }^{25}$ Ibidem, s. 358. Co ciekawe, Rachel Colls zauważa, że Julia Kristeva, opisując różnego rodzaju wydzieliny, które naruszają cielesny podział na to, co wewnętrzne i zewnętrzne, nie wspomina o tłuszczu jako kolejnej substancji cielesnej. Por.: ibidem, s. 360 .

${ }^{26}$ Helen Malson, Anorexic Bodies and the Discursive Production of Feminine Excess, [w:] ed. Jane Ussher, Body Talk: The Material and Discursive Regulation of Sexuality, Madness and Reproduction, Routledge, London, New York 1997, s. 237.

${ }^{27}$ Por.: Elspeth Probyn: Eating disgust, feeding shame..., op. cit., s. 133.

${ }^{28}$ Por.: Elspeth Probyn: Everyday Shame, op. cit. 
akcja ciała, może odwrócić ten porządek i wywrócić wnętrze na zewnątrz i zewnętrzne do wewnątrz ${ }^{29}$. Dlatego też wstyd, będący przeciwieństwem dumy, sam w sobie zawiera potencjał i może zostać wykorzystany jako produktywna siła, wywracająca to, co uwewnętrznione na zewnątrz. Takim uzewnętrznieniem wstydliwości jest publiczne manifestowanie i celebrowanie „niepasujących” ciał. Wywołując wstyd po obu stronach (patrzącego/ ej i oglądanego/ej), tworzy się osobliwa „strefa kontaktu”, która wytwarza nowego rodzaju sąsiedztwo pomiędzy podmiotami.

Rachel Colls, wykorzystując koncepcję Karen Barad, pisze o otyłości jako cielesnej intra-aktywności, będącej przeciwstawieniem wchodzącej w różne zależności interaktywności ${ }^{30}$. Ciało otyłe, będące zarazem ciałem „niepasującym", wchodzi nie tylko w relacje z samym sobą, ale też z otaczającą rzeczywistością, co, zdaniem badaczki, może wytwarzać pozytywny potencjał:

Przestrzenność ciała powinna być postrzegana jako nieustannie toczący się proces (prze) budowy poprzez przerabianie granic, które odgrywają produktywną rolę w materializowaniu zjawiska. W tym przypadku nieustająca i wielokrotna materializacja tłuszczu lub tłuszczyku może być osiągnięta poprzez nowe przestrzenie (fałdki i marszczenia) i języki (siła i rozmach), które wyłaniają się, kiedy ciało jest rozumiane przez swoje zdolności intra-aktywne ${ }^{31}$.

„Zdolności intra-aktywne” oznaczają nieustanne negocjowanie własnych granic poprzez wchodzenie w aktywne relacje ze środowiskiem, co doprowadza do zniesienia szczelnej granicy pomiędzy wnętrzem i zewnętrzem, normą i zaburzeniem. W efekcie, skupienie się na zdolnościach intra-aktywnych cielesnej materii ilustruje sposoby, dzięki którym ciała otyłe przekraczają produkujące je normy.

Innymi słowy, chodzi przede wszystkim o reorganizację języka i przestrzeni, w której funkcjonują zarówno ciała dopasowane, jak i wykluczone. Według Probyn, postulowanie zwiększenia częstotliwości reprezentacji ciał

${ }^{29}$ Por.: Elspeth Probyn: Eating disgust, feeding shame..., op. cit., s. 142.

${ }^{30}$ W koncepcji Karen Barad „intra-akcja” zostaje wyraźnie przeciwstawiona pojęciu interakcji, albowiem ta ostatnia zakłada istnienie niezależnych bytów. Rozróżnienie to precyzyjnie wyjaśnia Shannon Sullivan: „Termin «interakcja» sugeruje dwie niezależnie ustanowione jednostki wkraczające ze sobą w wymianę lub związek". (Shannon Sullivan, Living Across and Through Skins: Transactional Bodies, Pragmatism, and Feminism, Indiana University Press, Bloomington 2001, s. 1.) Przy intra-akcji chodzi o płynny proces przechodzenia, podczas gdy interakcja jest relacją statyczną. Intra-akcja zakłada ustanowienie nowej relacji, która wyklucza możliwość istnienia w separacji i polega na „epistemologicznej nierozdzielności pozostających w sprawczej intra-akcji składników”. Karen Barad, Posthumanistyczna performatywność: ku zrozumieniu, jak materia zaczyna mieć znaczenie, przeł. Joanna Bednarek, [w:] red. Agnieszka Gajewska, Teorie wywrotowe. Antologia przekładów, Wydawnictwo Poznańskie, Poznań 2012, s. 340.

${ }^{31}$ Rachel Colls, op. cit., s. 363. 
o rozmiarach plus i o społeczną akceptację otyłości niewiele zmieni w sytuacji, w której klasa, płeć i lokalizacja ustalają kryteria otyłości czy nadwagi. Żyjemy w społeczeństwie, w którym nie istnieje język, za pomocą którego można mówić o ciele i o jedzeniu ${ }^{32}$. „Musimy [...] słuchać tych głosów, które złapane zostały, niczym w matrix, w kompleks przemiany globalnych i lokalnych warunków"33. Chodzi głównie o ponowne przemyślenie dystansu między ciałem a jego reprezentacją, o wypełnienie wyrwy, jaka powstała między materią a językiem, słowem, o przekroczenie dualistycznych podziałów i zniesienie binarnych opozycji.

\section{Spektakl patologicznego ciała}

Reprezentacja ciała chorego lub patologicznego, a więc „niepasującego”, stała się wyrazem poszukiwań nowej estetyki w sztuce modernizmu, a rodowodu tego typu przedstawień możemy poszukiwać w szpitalach psychiatrycznych, zwłaszcza w klinice Salpêtrière ${ }^{34}$. Zjawisko inwazji patologii w dziedzinę sztuki, a także zainteresowanie artystów medycznymi portretami chorych ciał nosi kilka nazw: outsider art, „sztuka psychotyczna”, art brut czy „,sztuka niezwykła" ${ }^{35}$. Roger Cardinal w swojej książce Outsider Art, wydanej w 1972 roku, opisuje nie tylko sztukę osób chorych psychicznie, ale też rozmaite sposoby reprezentacji ciał ekscentrycznych, odmiennych i niepasujących właśnie. W tego typu praktykach, których celem jest przedstawienie ciała doświadczającego bólu (body-in-pain), krytycy i krytyczki sztuki dostrzegają wzrastające zainteresowanie grupami marginalizowanymi, których reprezentacja podważa ideę naprawczego i autorytatywnego kanonu sztuki zachodniej ${ }^{36}$.

Współcześnie choroby zaburzeń odżywiania również wkraczają w przestrzeń sztuki i są tymi głosami, których poszukuje Elspeth Probyn. W przeciwieństwie do kobiet otyłych, anorektyczki niekoniecznie postrzegają swoje ciała jako odrażające; wiele kobiet wręcz manifestuje i eksponuje swoją wychudzoną sylwetkę, nawet jeśli dla obserwatora jest to niewygodne

${ }^{32}$ Por.: ibidem, s. 122.

33 Elspeth Probyn, Fat, Feelings, Bodies. A Critical Approach to Obesity, [w:] eds. Helen Malson, Maree Burns, Critical Feminist Approaches to Eating Dis/orders, Routledge, New York 2009, s. 121.

34 Por.: Allan Beveridge, A Disquieting Feeling of Strangeness?: The Art of the Mentally Ill, „Journal of the Royal Society of Medicine” 2001, vol. 94, issue 11, s. 595; Gemma Blackshaw, The Pathological Body: Modernist Strategising in Egon Schiele's Self-Portraiture, „Oxford Art Journal” 2007, vol. 30, issue 3, s. 382.

35 Por.: Allan Beveridge, op. cit., s. 595.

${ }^{36}$ Por.: ibidem, s. 599. 
i nieprzyjemne ${ }^{37}$. Anoreksja staje się zatem nowym zjawiskiem cielesności i postrzegana jest nawet w kategoriach współczesnej odmiany body $\operatorname{art}^{38}$. Bogna Olszewska pisze:

Jedną z intencji body-artu jest wyrwanie ciała z tej opresji nadzoru przez manifestację indywidualnej kontroli nad ciałem i ustanawianie tożsamości w sposób niezależny od dominującego w kulturze dyskursu. To zbliża oczywiście body-art do zagadnienia anoreksji jako najwyższego stopnia dyscyplinowania ciała, włączając w to pośrednią władzę nad jego fizjologią ${ }^{39}$

Prowokacyjna teza Olszewskiej, obnażająca przy okazji coraz to bliższe korelacje choroby i sztuki, znajduje swoje potwierdzenie w kulturowej fascynacji anoreksją. Interesującym przykładem na wykorzystanie wizerunku anorektyczek jest projekt niemieckiej fotografki, Ivonne Thein, który nosi tytuł The Thirty-Two Kilos ${ }^{40}$. Zainspirowana zdjęciami zamieszczonymi na stronach Pro-Any, Thein przedstawia ekstremalnie wychudzone ciała kobiet bez twarzy, pozujących jak profesjonalne modelki. Szokujące prace niemieckiej artystki w przewrotny sposób eksponują zjawisko patologiczne, będące wynikiem promowanego przez kulturę Zachodu kultu piękna. Modelki Thein nie są anorektyczkami; wszystkie zdjęcia zostały cyfrowo przetworzone i, jeśli porównamy fotografie do rzeczywistych kształtów anorektyczek, to różnica jest znacząca (anorektyczki prawdopodobnie nie byłyby w stanie przybrać tego typu pozy). Równie kontrowersyjna, co interesująca jest działalność sióstr bliźniaczek, Anguelique i Liesbeth Raevens ${ }^{41}$, które ze swoich ciał uczyniły obiekty sztuki. Obie siostry ważą razem dokładnie tyle samo, co zdrowa osoba i prezentują swoje wychudzone ciała w celu wywołania wstrząsu wśród publiczności (dlatego też swoje prace określają mianem aesthetic terrorism).

Ciała kobiet dotkniętych problemem zaburzeń odżywiania snują swoje własne narracje - w literaturze coraz popularniejszy staje się nowy rodzaj twórczości określanej mianem écriture faminine (w języku francuskim

${ }^{37}$ Por.: Susie Orbach, Hunger Strike. The Anorectic's Struggle as a Metaphor for Our Age, W.W. Norton, London 1986, s. 157.

${ }_{38}$ Zob.: Lydia Brawner, Linda Montano, Anorexia Nervosa and an Art of Hunger, „Women \& Performance: A Journal of Feminist Theory” 2008, vol. 18, issue 2, s. 127-132.

39 Bogna Olszewska, Widowisko cielesności. Czy anoreksja może być nazywana body-art?, „Kultura Liberalna” 11 listopada 2009; dostępne przez: http://kulturaliberalna. $\mathrm{pl} / 2009 / 11 / 09 / o l s z e w s k a-w i d o w i s k o-c i e l e s n o s c i-c z y-a n o r e k s j a-m o z e-b y c-n a z w a n a-b o d y-$ art/ (04.10.2011).

${ }^{40}$ Prace Ivonne Thein dostępne są na stronie internetowej artystki: http://www.ivonnethein.com/ (13.09.2012). Tytuł został zainspirowany postacią francuskiej modelki Isabelle Caro, która wystąpiła w kampanii No Anorexia.

${ }^{41}$ Prace artystek dostępne są na stronie internetowej: http://www.laraeven.nl/index. html (10.09.2012). 
famine oznacza 'głód') lub écriture taille zero. Anorektyczka, podobnie jak histeryczka, jest artystką ciała, performerką nieświadomie obnażającą absurdalne standardy piękna współczesnej kultury. Josephine Brain obala pogląd, wedle którego bulimiczki i anorektyczki miałyby wytwarzać uległe ciała; przeciwnie, ich działania, zdaniem Brain, w pełni subwersywne, zaburzają binarny porządek płci i ról społecznych ${ }^{42}$. To kolejne pokolenie zbuntowanych cór patriarchatu, żyjących w dobie kultury konsumpcyjnej, będących całkowitym zaprzeczeniem ideału hiperkobiecości. Modelki Thein nie są już zależne od spojrzenia męskiego podmiotu, jak histeryczki, gdyż widok ich ciał zmusza do odwrócenia wzroku.

Kolejnym przykładem sztuki sytuującej się w tradycji przedstawiania ciała w bólu jest wystawa fotografa Victora Boulleta Kate in Bed on Day $1^{43}$, ukazująca cierpienie kryjące się za pozornym pięknem lansowanym przez przemysł chirurgii kosmetycznej. Operacje plastyczne pozwalają nam stać się tym, kim chcemy być, zgrabnie usuwając siebie z siebie. W podobnym tonie utrzymane są prace z wystawy Proforma, wspomnianej wcześniej Ivonne Thein, która prezentuje ciała wykrojone na miarę, ciała sztuczne i plastikowe, ale dopasowane do idealnych standardów. A jednak plastik, będący symbolem zmienności i transformacji, wykazujący się zdolnością łączenia naturalnego ze sztucznym, podmiotu z przedmiotem, jest symbolem podmiotu w procesie, łaknieniem nieustannej przemiany ${ }^{44}$. Z kolei prace włoskiej artystki, Vanessy Beecroft ${ }^{45}$, również przedstawiają szereg kobiet wyglądających podobnie: biernych, często nagich i wystawionych na widok publiczny. Celem performance'ów artystki jest nawiązanie osobliwej komunikacji pomiędzy modelkami a publicznością i ich wzajemne spotkanie między wstydem jednych a oczekiwaniami drugich.

Jednym z ważniejszych kobiecych głosów dekonstruujących zachodnie ideały piękna jest twórczość Niki de Saint Phalle, a zwłaszcza cykl rzeźb o nazwie Nana, uosabiających archetypowe przedstawienie kobiecej płodności i krągłych kształtów. Tańczące, kolorowe i emanujące radością rzeźby de Saint Phalle są symbolem kobiecości wyzwolonej spod obowiązujących ideałów kobiecości najpełniej uosabianych przez Jacqueline Kennedy oraz Twiggy. Pierwszą wystawę Nany w 1965 roku w paryskiej Galerie Iolas Niki

${ }^{42}$ Por.: Josephine Brain, Anorexia as a Subversive Bodily Act: Psychic Incorporation or Body Narratives of the Self?; dostępne przez: http://www.women.it/cyberarchive/files/ brain.htm (01.05.2012).

43 Omawianą pracę artysty można zobaczyć na stronie internetowej: http://www.hfcollection.org/kate-in-bed-on-day-1/ (27.02.2013).

44 Por.: Kim Toffoletti, op. cit., s. 68.

45 Prace artystki dostępne są na stronie internetowej: http://www.vanessabeecroft. com/frameset.html (27.02.2013). 
nazwała Nana Power - rzeźby miały ponad pięć metrów wysokości i stały się symbolem monumentalnego matriarchatu.

Innym, niezwykle interesującym w tym kontekście projektem artystycznym, jest rzeźba wykonana przez artystę Johna Isaacsa ${ }^{46}$, przedstawiająca monumentalną, fikcyjną i anonimową figurę, która nie tyle uosabia „potworność otyłości”, co ukazuje ciało jako miejsce wewnętrznych konfliktów, doświadczanych w dobie powszechnej konsumpcji. Artysta zdaje się pytać „jeśli nie teraz, to kiedy?” - to właśnie teraz jest tym momentem w czasie, w którym należy uświadomić sobie społeczną apatię i ukrywanie poczucia winy. Przy czym hipertroficzna, zdeformowana i wręcz karykaturalna sylwetka, jaką przedstawia rzeźba Isaacsa, jest w tym przypadku jedynie kozłem ofiarnym, wytworem i produktem konsumpcyjnej machiny. Co więcej, przedstawione przez rzeźbiarza ciało nie tylko nie przypomina ludzkich kształtów, ale też uniemożliwia przypisanie mu konkretnej płci czy tożsamości.

Przedstawianie ciała doświadczającego bólu, doprowadzonego do ekstremum, to nie tylko tworzenie sztuki zaangażowanej, ale też sposób wymuszenia kontaktu z odbiorcą, jak pisze Gemma Blackshaw ${ }^{47}$. Ciała niepasujące, okaleczone i odrażające, cechują się zdolnością do wywoływania szoku, wybijają z bezpiecznego azylu myśli i to jest, moim zdaniem, centralny zamysł wyżej wymienionych projektów artystycznych.

Ciała pasujące i niepasujace to ciała wyrwane z kontekstu kulturowego, historycznego, geograficznego i społeczno-politycznego. Zachodni paradygmat jednego rozmiaru dla wszystkich ufundowany jest na binarnym porządku przykrawania do ideału i odrzucania. Zdaniem Rosemarie Garland-Thomson, należy wziąć pod uwagę wszystkie konteksty, które dotyczą naszych ciał. Chodzi przede wszystkim o uwzględnienie nieustającego i dynamicznego spotkania ciała ze środowiskiem, w którym się ono znajduje. Celebracja różnorodności, a także zniesienie podziału na to, co zachodnie i niezachodnie oraz wynalezienie nowego języka są alternatywną „ideą dysonansu”, jak chce badaczka, znoszącą podział między podmiotami dopasowanymi i niepasującymi, widzialnymi i niewidzialnymi. Paradoksalnie, podmioty niedopasowane mają zdolność do produkowania spójnych narracji opowiadających o doświadczeniach poniżenia i marginalizowania. Te opowieści, będące nowym kontekstem teorii feministycznych, mimo że przepełnione bólem, wnoszą również nowy potencjał estetyczny. Zwróćcie uwagę na okrągłe kształty Nany - ona jest piękna i się śmieje.

${ }^{46}$ Zdjęcie rzeźby, zatytułowanej If not now then when?, dostępne jest na stronie internetowej: http://johnisaacs.net/works_2010/works_2010_32.html (30.07.2013).

47 Por.: Gemma Blackshaw, op. cit., s. 396. 


\section{BIBLIOGRAFIA}

Barad Karen, Posthumanistyczna performatywność: ku zrozumieniu, jak materia zaczyna mieć znaczenie, przeł. Joanna Bednarek, [w:] red. Agnieszka Gajewska, Teorie wywrotowe. Antologia przekładów, Wydawnictwo Poznańskie, Poznań 2012.

Beveridge Allan, A Disquieting Feeling of Strangeness?: The Art of the Mentally Ill, „Journal of the Royal Society of Medicine" 2001, vol. 94, issue 11.

Blackshaw Gemma, The Pathological Body: Modernist Strategising in Egon Schiele's Self-Portraiture, „Oxford Art Journal” 2007, vol. 30, issue 3.

Bordo Susan, Unbearable Weight: Feminism, Western Culture, and the Body, University of California Press, Berkeley, Los Angeles 2003.

Braidotti Rosi, Metamorphoses: Towards a Materialist Theory of Becoming, Wiley, Cambridge 2002.

Brain Josephine, Anorexia as a Subversive Bodily Act: Psychic Incorporation or Body Narratives of the Self?; dostępne przez: http://www.women.it/cyberarchive/files/ brain.htm (01.05.2012).

Brawner Lydia, Linda Montano, Anorexia Nervosa and an Art of Hunger, „Women \& Performance: A Journal of Feminist Theory" 2008, vol. 18, issue 2.

Brotsky Sarah R., David Giles, Inside the „Pro-Ana” Community: a Covert Online Participant Observation, „Eating Disorders: The Journal of Treatment and Prevention” 2007, vol. 15, no 2.

Burns Maree, Eating Like an Ox: Femininity and Dualistic Constructions of Bulimia and Anorexia, „Feminism \& Psychology” 2004, vol. 14, no. 2.

Colls Rachel, Materialising Bodily Matter: Intra-Action and the Embodiment of „Fat”, „Geoforum” 2007, vol. 38, issue 2.

Day Katy, Tammy Keys, Anorexia/Bulimia as Resistance and Conformity in Pro-Ana and Pro-Mia Virtual Conversations, [w:] eds. Maree Burns, Helen Malson, Critical Feminist Approaches to Eating Dis/Orders, Routledge, New York 2009.

Garland-Thomson Rosemarie, Misfits: A Feminist Materialist Disability Concept, „Hypatia” 2011, vol. 26, issue 3 .

Giles Banks Caroline, „There is No Fat in Heaven”: Religious Asceticism and the Meaning of Anorexia Nervosa, „Ethos” 1996, vol. 24, no. 1.

Gremillion Helen, The Cultural Politics of Body Size, „Annual Review of Anthropology” 2005, vol. 34 .

Jonvallen Petra, Sex Differentiation and Body Fat: Local Biologies and Gender Transgressions, „European Journal of Women's Studies” 2010, vol. 17, no. 4.

Klein Richard, Fat Beauty, [w:] eds. Jana Evans Braziel, Kathleen LeBesco, Bodies Out of Bounds. Fatness and Transgression, University California Press, Berkeley, Los Angeles, London 2001.

Kristeva Julia, Potęga obrzydzenia. Esej o wstręcie, przeł. Maciej Falski, Wydawnictwo Uniwersytetu Jagiellońskiego, Kraków 2007.

LeBesco Kathleen, Jana Evans Braziel, Editors' Introduction, [w:] eds. Jana Evans Braziel, Kathleen LeBesco, Bodies Out of Bounds. Fatness and Transgression, University California Press, Berkeley-Los Angeles-London 2001.

Malson Helen, Anorexic Bodies and the Discursive Production of Feminine Excess, [w:] ed. Jane Ussher, Body Talk: The Material and Discursive Regulation of Sexuality, Madness and Reproduction, Routledge, London, New York 1997.

Malson Helen, Jane Ussher, Beyond This Mortal Coil: Femininity, Death and Discursive Constructions of the Anorexic Body, „Mortality” 1997, vol. 2, issue 1. 
Malson Helen, The Thin Woman. Feminism, Post-structuralism and the Social Psychology of Anorexia Nervosa, Taylor \& Francis, London 1998.

Olszewska Bogna, Widowisko cielesności. Czy anoreksja może być nazywana body-art?, „Kultura Liberalna” 11 listopada 2009; dostępne przez: http://kulturaliberalna.

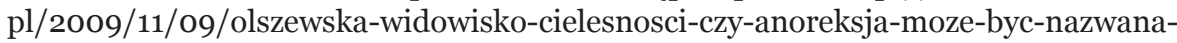
body-art/ (04.10.2011).

Orbach Susie, Fat is a Feminist Issue, Arrow Books, London 1998.

Orbach Susie, Hunger Strike. The Anorectic's Struggle as a Metaphor for Our Age, W.W. Norton, London 1986.

Orbach Susie, Losing Bodies, „Social Research” 2011, vol. 78, no. 2.

Probyn Elspeth, Eating disgust, feeding shame, [w:] eadem, Carnal Appetites. Food, Sex, Identities, Routledge, London, New York 2005.

Probyn Elspeth, Everyday Shame, „Cultural Studies” 2004, vol. 18, no. 2-3.

Probyn Elspeth, Fat, Feelings, Bodies. A Critical Approach to Obesity, [w:] eds. Helen Malson, Maree Burns, Critical Feminist Approaches to Eating Dis/orders, Routledge, New York 2009..

Showalter Elaine, Hystories. Hysterical Epidemics and Modern Culture, Columbia University Press, New York 1997.

Squire Sarah, Anorexia and Bulimia: Purity and Danger, „Australian Feminist Studies” 2003, vol. 18, issue 40.

Sullivan Shannon, Living Across and Through Skins: Transactional Bodies, Pragmatism, and Feminism, Indiana University Press, Bloomington 2001.

Toffoletti Kim, Cyborgs and Barbie Dolls. Feminism, Popular Culture and the Posthuman Body, I.B. Tauris, London, New York 2007.

Vigarello Georges, Historia otyłości od średniowiecza do XX wieku, przeł. Anna Leyk, Wydawnictwo Aletheia, Warszawa 2012.

Wolf Naomi, The Beauty Myth: How Images of Beauty are Used Against Women, Morrow, New York 1991. 